\title{
Liu Xiaobo. Un intellectuel chinois face à la tradition et au
} nationalisme

Frank Muyard

\section{Citer ce document / Cite this document :}

Muyard Frank. Liu Xiaobo. Un intellectuel chinois face à la tradition et au nationalisme. In: Perspectives chinoises, $\mathrm{n}^{\circ} 40,1997$. p. 29;

doi : https://doi.org/10.3406/perch.1997.2886

https://www.persee.fr/doc/perch_1021-9013_1997_num_40_1_2886

Fichier pdf généré le 24/04/2018 


\section{Liu Xiaobo}

\section{Un intellectuel chinois face à la tradition et au nationalisme}

ES deux textes de Liu Xiaobo présentés ci-dessous ont été écrits, le premier en 1989, le second en 1994. Tous deux se penchent sur la question du rapport de la culture chinoise à l'Occident, l'un consacré à la pensée critique, l'autre s'attachant au problème du nationalisme des élites chinoises. Ils posent ainsi avec acuité les questions fondamentales auxquelles font face tous ceux qui tentent, comme Liu 'iaobo, de promouvoir la liberté de l'individu et l'autonomie de la pensée en Chine.

Longtemps un pur admirateur de l'Occident, Liu Xiaobo s'est fait connaître en 1986 par sa critique virulente de la littérature chinoise contemporaine et son rejet de la culture traditionnelle. Attaquant les thèses de Li Zehou, à l'époque maître incontesté du renouveau de la pensée philosophique et esthétique, il poursuit jusqu'en 1989 son appel à une occidentalisation en profondeur de la culture chinoise (1). En avril 1989, Liu Xiaobo interrompt son séjour à NewYork pour rentrer en Chine et prendre part au mouvement étudiant de contestation. Emprisonné au lendemain de la répression militaire du 4 juin 1989, il est dénoncé comme l'un des cerveaux du mouvement. Relâché au bout d'un an et demi après une auto-critique acceptable pour le pouvoir chinois (2), Liu Xiaobo est de nouveau arrêté en octobre 1996 à la suite de la publication à Hong-Kong d'un article réclamant des réformes politiques en Chine (cf. Perspectives chinoises, $n^{\circ} 37$ ). II est, depuis, toujours en détention administrative.

Le premier texte traduit ici, "Réflexions d'un anti-traditionnaliste", est le dernier que Liu Xiaobo ait écrit avant son arrestation en 1989. Pour saisir à la fois sa portée et ses limites, il est nécessaire de le replacer dans le contexte de sa rédaction. Ecrit en partie à New-York, en partie à Pékin, et faisant suite à un séjour de huit mois à l'étranger, cet article révèle en effet tant une certaine naïveté envers la culture occidentale que l'influence substantielle des courants d'idées de l'époque, chinois comme occidentaux, sur la question de la modernité.

Ce premier séjour de Liu Xiaobo à l'étranger est marqué par une "révélation" du monde extérieur qui lui fait prendre conscience à la fois des limites de sa réflexion et des problèmes propres à l'Occident. II signale aussi la fin de sa sacralisation de la culture occidentale et la réorientation de son système de référence critique sur les seuls thèmes de la réflexivité et de l'autonomie de l'individu. La reprise de ces deux principes majeurs de la modernité des "Lumières", qui apparait dans le texte, va lui permettre de se distancer à la fois du particularisme chinois et de l'idéalisme de l'Occident. Répondant aux problèmes structurels auxquels font face les intellectuels chinois devant le développement moderne de la Chine, ce texte amorce ainsi une véritable pensée philosophique capable d'articuler les questions de la modernité de l'Empire du Milieu et de l'accomplissement individuel.

La maturation de son approche de l'Occident et de sa critique des intellectuels chinois est manifeste dans le second article. Ecrit à l'automne 1994, il réagit cette fois-ci à la vague de nationalisme qui touche la Chine depuis le début des années 1990. Il dénonce la collusion des élites avec le pouvoir, et souligne à quel point cette nouvelle vague répète les incohérences des réactions anti-occidentales qui jalonnent l'histoire moderne chinoise. Finalement, posant la question du rapport de l'intellectuel à soi, au régime et à l'Occident, Liu Xiaobo montre que ce nationalisme ne s'inscrit aucunement dans un mouvement d'émancipation mais, au contraire, toujours dans le même cercle de la soumission et de l'aliénation idéologique.

Frank Muyard 